evidence suggests that it is still found in the Kete Krachi area and that it is still the subject of ritual hunting. The flooding may very well increase its habitat in West Africa, but it is presumed to feed on aquatic plants and on vegetation growing on or overhanging the banks. It would eat vegetation that no other animals would convert into edible animal protein, and it might help in controlling aquatic plants, as it does in British Guiana. In theory only it is already fully protected. There is every reason to enforce this protection rigidly if there is to be any hope of building up a sufficient stock to allow controlled cropping later.

The Oti River Valley, about the fauna of which little is known, will form a large north-east arm of the lake. The river meanders through grassland, some of it marshy, and there are few people. A report that the marshbuck, or sitatunga, is here could well be true; it would be the first record for Ghana of this specialized member of the bushbuck family, though it is well known in the coastal regions of Nigeria and near Lake Chad. The terrain makes detailed reconnaissance difficult, nor would trapping and rescue operations be feasible in a sitatunga's habitat, but in this gently undulating valley country several extensive flat islands will be left. These should at least serve as a temporary sanctuary for any sitatunga, even though the present marsh habitat completely disappears, and it is possible that some parts of these islands will in time become swampy and covered with a wetter type of vegetation.

\title{
Guide to South African Wildlife
}

During recent years there have been several useful handbooks on African wildlife, but one of the main gaps has been where least expected, in South Africa. The Game Animals of Southern Africa, by C. T. Astley Maberley, Nelson, 18s. $6 \mathrm{~d}$. fills it in a most comprehensive manner, and moreover does a great service by gathering together so much valuable data. The assembled biological notes of many species make fascinating reading, and for the most part they are commendably accurate. Of course there is the occasional slip, and a few avoidable gaps in the recorded knowledge both of habits and ranges. It is a pity also to have emphasized the sores so commonly seen in the black rhinoceros, when it has long been established that they are merely a form of dermatitis.

The book will admirably serve its stated purpose, of providing a most useful guide for all visitors to South Africa and its parks and reserves, but because it will also be much used by those who are closely interested in the study of mammals, two things are unfortunate and one of them also tiresome. The first, that in scientific terminology the author does not follow up-to-date check lists ; the second that there is no index of either trivial or scientific names. The title also could have been improved: whatever the connotation of "game animals", the term is one to be avoided and surely can never be referable to hyenas, mongooses, jackals, and monkeys ?

The author has an enviable reputation for the skill and attractiveness of his wildlife sketches. With very few exceptions, among animals with which he has not been too familiar, they evidence all those details which characterize a truly observant field naturalist. 'Indubitably the book will have a wide circulation and indeed deserves it. 